\title{
Genetic and environmental factors in hypospadias
}

\author{
C Stoll, Y Alembik, M P Roth, B Dott
}

\begin{abstract}
A case control study of hypospadias was performed from 1979 to 1987 in Alsace, north-eastern France. A total of 176 out of 60847 male infants had hypospadias giving a prevalence at birth of 2.89 per 1000 male newborns; $15 \cdot 3 \%$ of all infants with hypospadias also had other malformations. Renal and urinary tract malformations were present in $37.0 \%$ of the infants with hypospadias and other additional malformations. None of the numerous aetiological factors which were studied was correlated with hypospadias except low weight of the placenta. The recurrence risk for brothers was $17.0 \%$ (an empirical risk of about 1 in 6 ) and the heritability coefficient was $\mathbf{5 6 . 9 \%}$. First degree relatives of infants with hypospadias had more malformations other than hypospadias than controls. These results have to be taken into consideration for genetic counselling.
\end{abstract}

The epidemiology of hypospadias, one of the most common urogenital malformations, has been extensively reported since the first study by Sorensen ${ }^{1}$ in Denmark from 1910 to 1945 , which was really designed to elucidate the heredity of the malformation. Other studies followed: in South Wales on 92982 infants, ${ }^{2}$ in Rochester, Minnesota, ${ }^{3}$ in Sweden by Avellan $^{4}$ and Svensson ${ }^{6}$ from 1952 to 1972, in Hungary, ${ }^{7}$ in six Latin American countries, ${ }^{8}$ and in British Columbia where Leung et $a l^{9}$ found 314 cases among 259696 male live births during 1966 to 1981 . Recently, data ( 8122 boys with hypospadias) from seven malformation surveillance systems around the world (Europe, Mexico, and South America) have been published. ${ }^{10}$ In addition, many other epidemiological studies on malformations in general have been published, in which data on hypospadias are given.

Fewer studies on the aetiology of hypospadias are available and most of them have focused on its inheritance. Autosomal recessive inheritance with incomplete expression was discussed by Sorensen, ${ }^{1}$

Institut de Puériculture, Hôpital Civil, 23 Rue de la Porte de l'Hôpital, 67091 Strasbourg, France.

C Stoll, Y Alembik, M P Roth, B Dott

Correspondence to Professor Stoll. and autosomal dominant inheritance with low penetrance was proposed by Kemp, ${ }^{11}$ Gates, ${ }^{12}$ and Lowry and Kliman, ${ }^{13}$ but most authors favour a multifactorial model. ${ }^{5} 71415$ According to this model, multiple genetic factors combine with environmental factors during early pregnancy, between the eighth and fourteenth week after fertilisation, when hypospadias occurs from non-fusion of the urethral folds or lack of cannulation of the penile glans or both. Various maternal variables have been thought to be associated with the birth of cases of hypospadias, such as drug consumption before (oral contraceptives) or during pregnancy (progestins). ${ }^{3}{ }^{5} 16-21$ Low birth weight ${ }^{3} 7815-17222^{23}$ and birth order ${ }^{815}{ }^{21}$ have been found to be associated with the birth of boys with hypospadias.

In the present paper, data on 176 cases of hypospadias delivered in Alsace, north-eastern France, during the period 1979 to 1987 are reported. A case control study allowed the examination of the association of genetic and environmental factors in the origin of hypospadias.

\section{Material and methods}

The material for this study came from 118265 consecutive births of known outcome, including 814 stillborn babies, entered in our registry of congenital malformations, which is described elsewhere. ${ }^{24}$ Briefly, the newborn infants in 11 hospitals were examined during the period 1 January 1979 to 31 December 1987. The regions involved were the city of Strasbourg (an urban area) and the area defined as the 'Departement du Bas-Rhin' in which Strasbourg is situated (a rural area). All newborn babies were registered within the first nine days after birth, as well as all fetuses with a minimum age of 20 weeks. No delivery took place at home in the area under study.

When a suspected or a confirmed case was notified, the requested information was checked by a doctor in available records: prenatal consultation records, maternity files, neonatal unit files, necropsy reports, outpatient clinic files, and paediatric and surgical files. Family histories were taken during the mother's stay in the maternity hospital. All first degree relatives were examined. Renal ultrasonography was carried out on the index cases only.

The hypospadias was classified as distal (glandular or coronal) with the orifice on the glans or in the 
sulcus, penile with the urethral orifice on the penis, or perineal with the urethral orifice in the perineum.

For each case more than 50 factors included in the registration forms were studied: parity and previous pregnancies, parental age, residence, education, ethnic origin, length, head circumference, and weight at birth, genetic factors (consanguinity of parents, inheritance, cytogenetics, occurrence in twins), environmental factors, seasonality, and pregnancy. Follow up information was obtained through the paediatric surgeon and the physician in charge of the infant's care.

For each malformed child a control was chosen. The control was a normal child of the same sex born immediately after the malformed child in the same maternity hospital.

For seasonality studies the monthly occurrences of all normal births from 1979 to 1987 were chosen as the denominator for control rates. The sex ratios were compared to the normal newborn population, as was the residence.

Statistical analysis was performed using the Statistical Analysis System (SAS) package. ${ }^{25}$ Statistical comparisons were done using the $\chi^{2}$ test or Fisher's exact test for the qualitative characteristics under study, and Student's $t$ test for the quantitative data. Multiple linear regression and the spectra procedure were used for seasonality studies. Odds ratio values were determined for the risk factors.

\section{Results}

During the study period, 176 cases of hypospadias out of a total of 118265 births were detected, representing a prevalence at birth of 1.48 per 1000 . The rate calculated on male births $(60847)$ was $2 \cdot 89$ per 1000.

The number of cases by year were: 15 in 1979, 20 in 1980, 13 in 1981, 24 in 1982, 27 in 1983, 20 in 1984, 26 in 1985, 12 in 1986, and 19 in 1987.

All were livebirths. Diagnosis was performed at birth in 156 cases, during the first week of life in 10 cases, and during the first year of life in seven cases. Three cases in whom hypospadias was associated with other malformations were diagnosed prenatally.

The distribution of the three types of hypospadias was 121 distal $(68 \cdot 7 \%), 44$ penile $(25 \cdot 0 \%)$, and 11 $(6 \cdot 2 \%)$ perineal. There were $149(84.6 \%)$ isolated cases and $27(15 \cdot 3 \%)$ associated with other malformations. Genital malformations like undescended testis, hydrocele, and scrotum malformations, regarded as closely associated with the pathogenetic mechanism causing hypospadias, ${ }^{10}$ were considered as isolated cases. The other malformations are listed in table 1 . The expected number of cases of hypospadias with another malformation of a specific type was calculated from the frequency of that specific malformation in multimalformed infants without hypospadias that had
Table 1 Frequency of specific malformations in infants with hypospadias and two or more other unrelated malformations, compared with children with two or more major malformations excluding hypospadias. The expected numbers for each malformation are calculated by standardisation for our registry.

\begin{tabular}{lcc}
\hline Malformations & $\begin{array}{c}\text { No of } \\
\text { cases }\end{array}$ & $\begin{array}{c}\text { Expected by } \\
\text { standardisation }\end{array}$ \\
\hline Agenesis of kidney & 3 & $12 \cdot 1$ \\
Vesicoureteric reflux & 5 & $3 \cdot 8$ \\
Other urinary tract malformation & 4 & $18 \cdot 2$ \\
Congenital heart disease & 7 & $52 \cdot 0$ \\
Limb malformation & 3 & $34 \cdot 0$ \\
Syndactyly & 2 & $10 \cdot 2$ \\
Cerebral anomaly & 3 & $35 \cdot 3$ \\
Intestinal atresia & 1 & $13 \cdot 5$ \\
Oesophageal atresia & 1 & $4 \cdot 1$ \\
Other gut malformation & 1 & $2 \cdot 6$ \\
Cleft lip/palate & 1 & $21 \cdot 2$ \\
Cutaneous anomaly & 2 & $2 \cdot 2$ \\
Facial dysmorphism (non- & 3 & $5 \cdot 1$ \\
$\quad$ syndromic) & & \\
\hline
\end{tabular}

been registered during the period 1979 to $1987 . .^{10}$ Observed numbers of infants with different types of hypospadias in the presence of other malformations are shown in table 2 .

Ten out of 27 multiply malformed infants $(37 \cdot 0 \%)$ had a urinary tract malformation (five vesicoureteral reflux, two unilateral agenesis of the kidney, and one each of urethral valvula, horseshoe kidney, and bilateral duplicated kidney). Another child had a horseshoe kidney with oesophageal atresia and ventricular septal defect. Four other children had congenital heart defects, two of them with cerebral atrophy. Three cases had intestinal malformations: one atresia, one situs inversus, one Hirschsprung's disease. One case had Opitz syndrome, one had ring chromosome 18 , and one had trisomy lq. There was one case of cleft palate, one of adrenal hypoplasia, one of syndactyly, one of polydactyly, and two of facial dysmorphism.

The factors studied in relation to hypospadias are listed in table 3 and compared to controls.

\section{ENVIRONMENTAL FACTORS}

There was no demonstrable difference in our study between mothers of infants with or without hypospadias with regard to parity, previous abortion, menarche, characteristics of menstrual cycle, parental

Table 2 Observed $(O)$ numbers of infants with different types of hypospadias in the presence of another malformation. Expected numbers $(E)$ are calculated from the distribution among infants with isolated hypospadias. Mean number of malformations per infant is also given $(N)$.

\begin{tabular}{lccc}
\hline Type of hypospadias & $\mathrm{O}$ & $\mathrm{E}$ & $\mathrm{N}$ \\
\hline Glandular or coronal & 4 & $15 \cdot 8$ & $2 \cdot 5$ \\
Penile & 17 & $5 \cdot 7$ & $2 \cdot 6$ \\
Perineal & 6 & $1 \cdot 4$ & $3 \cdot 3$ \\
\hline
\end{tabular}


Table 3 Factors studied in relation to hypospadias.

\begin{tabular}{|c|c|c|}
\hline Factors & Odds ratio & $\begin{array}{l}95 \% \text { confidence } \\
\text { interval }\end{array}$ \\
\hline $\begin{array}{l}\text { Birth weight } \\
\text { Birth length } \\
\text { Head circumference } \\
\text { Weight of placenta } \\
\text { Oligohydramnios } \\
\text { Threatened abortion } \\
\text { Diabetes } \\
\text { Epilepsy } \\
\text { Hypertension } \\
\text { Fever } \\
\text { Influenza } \\
\text { Alcoholism } \\
\text { Oral contraceptive } \\
\text { Cigarettes } \\
\text { Drugs } \\
\text { Occupational exposure: mother } \\
\text { Exposure to } x \text { rays } \\
\text { Maternal age } \\
\text { Paternal age } \\
\text { Induced deliveries } \\
\text { Caesarean section } \\
\text { High age, primigravida } \\
\text { Early menarche, < } 10 \text { y }\end{array}$ & $\begin{array}{l}2 \cdot 05 \\
1.83 \\
1.88 \\
3.69 \\
0.97 \\
2 \cdot 10 \\
1.55 \\
1 \cdot 01 \\
0.87 \\
0.02 \\
1.00 \\
0.64 \\
0.49 \\
0.78 \\
0.06 \\
0.91 \\
0.82 \\
0.61 \\
0.77 \\
0.54 \\
0.70 \\
0.86 \\
0.68 \\
0.94\end{array}$ & 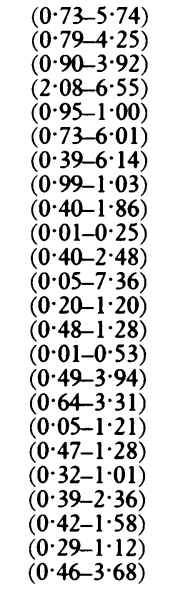 \\
\hline
\end{tabular}

age, residence (urban or rural), education, ethnic origin, birth length, birth weight, head circumference at birth, seasonality, exposure to toxins (alcohol, cigarettes) and radiation, oral contraceptives before conception, progestins and other drugs during pregnancy, and threatened abortions.

Of the mothers of infants with hypospadias, $53.9 \%$ were pregnant for the first time and $28.4 \%$ for the second time (controls $49 \cdot 4 \%$ and $32 \cdot 3 \%$ ). The differences are not significant (NS).

Mean birth weight was $3193 \mathrm{~g}$, controls $3297 \mathrm{~g}$ (NS). Length of gestation was shorter than 36 complete weeks in $10.8 \%$ of the cases, controls $11 \cdot 7 \%$ (NS).

Mean placental weight was lower than in controls (556 g v 515, table 3).

\section{GENETIC FACTORS}

There was no instance of parental consanguinity in the 176 cases under study. Karyotypes, which were obtained in 72 cases, were normal except in two patients, one ring chromosome 18 and one trisomy lq (the mother had a translocation $(1 ; 4)$ ). Seven twins were observed among our 176 index cases. Five of them had an unaffected twin brother and two an unaffected twin sister. Opitz syndrome, an inherited mendelian autosomal dominant condition, was present in one boy and in his father. Two fathers and eight brothers had hypospadias. Five mothers, three fathers, and four first degree relatives had malformations other than hypospadias (6.8\%): three had vesicoureteric reflux, two had limb malformations, three had cleft lip, one had anal atresia one had haemangioma, one had unilateral agenesis of the kidney, and one had ventricular septal defect (controls $3 \cdot 2 \%, \mathrm{p}<0 \cdot 01$ ).

\section{ESTIMATION OF HERITABILITY}

The method of Falconer ${ }^{26}$ was used, assuming multifactorial inheritance. Since hypospadias affects only males, only first degree male relatives were considered. Excluding twins as sibs and the patients with Opitz syndrome and chromosomal anomalies, the 176 index cases had a total of 47 brothers. Of these, eight had hypospadias (17.0\%). There were 223 first degree relatives including the fathers and the brothers. The heritability estimate for first degree relatives was calculated for $\mathrm{q}=0.00409$ in the general population of males, according to Chen and Woolley. ${ }^{15}$ In our sample $q=0.03587(8 / 223)$. The heritability for first degree relatives was $56 \cdot 9 \%$.

\section{Discussion}

The birth prevalence of hypospadias in our region is similar to those reported in other studies and countries. ${ }^{1-10}$ In the ICBDMS study, ${ }^{10}$ based on information from seven surveillance programmes located in different parts of the world, interprogramme variation in birth prevalence was observed. The authors believed that underascertainment alone could not explain this difference and that a true difference in birth prevalence exists, at least between South America and Mexico on one hand and Europe on the other. In the European countries examined, birth prevalence varies from 1.09 per 1000 in Denmark to $2 \cdot 11$ per 1000 in Hungary. Calzolari et $a l^{23}$ found a higher prevalence, $4 \cdot 1$ per 1000 male births, in Emilia Romagna: in this study, as in our series, no time trends were observed.

The severity of hypospadias in our sample was also similar to that recorded in other studies: $68 \cdot 7 \%$ were distal, $24 \cdot 8 \%$ penile, and $6.3 \%$ perineal. The frequency of the condition associated with other defects varies from 8 to $13 \% .^{28-1022}{ }^{23}$ In the ICBDMS study, ${ }^{10}$ no specific malformation appeared to be more common among multimalformed infants with hypospadias than among such children without hypospadias. In a previous study, out of 27 hypospadic multimalformed infants, Kallen and Winberg ${ }^{22}$ found six children with Pierre-Robin sequence or isolated micrognathia and five cases with severe renal agenesis or dysgenesis. In our cases, out of 27 multimalformed infants, three had unilateral renal agenesis, five had vesicoureteral reflux, and four others had other urinary system malformations (one horseshoe kidney, one urethral valve, and two duplicated kidneys). This finding of a high frequency of urinary tract malformations could be related to systematic use of ultrasound examination, which allowed early diagnosis. Further studies are needed to verify this point. Several specific malforma- 
tions appeared to be less common among our multiply malformed infants with hypospadias than among such infants without hypospadias (table 1), especially (apart from urorenal anomalies) congenital heart disease, limb malformations, cerebral anomalies, and cleft lip/palate. The difference between our study and the ICBDMS study ${ }^{10}$ may be the result of the small number of cases of each malformation and the fact that the ICBDMS study considered only infants with at least three malformations. More penile and perineal hypospadias were observed than expected in children with additional malformations (table 2 ).

First degree relatives of infants with hypospadias had more malformations other than hypospadias than the controls: $6.8 \% v 3.2 \%$. This result should be taken into consideration in genetic counselling.

Among the numerous variables considered in the present study we did not find a higher proportion of early menarche (10 years of age or less) as did Calzolari et $a l,{ }^{23}$ nor a relationship between hypospadias and maternal age or parity as did Kallen et $a l,{ }^{10}$ but our sample is probably too small to permit definitive conclusions. As in many other studies our boys with hypospadias tended to weigh less than normal, but the difference was not significant. Gestational age was not less in our cases. Placenta weight was decreased, which is in agreement with the suggestion of Kallen $e t a^{10}$ that growth retardation and premature birth could be an effect of placental insufficiency. No seasonal variation was observed in the present material unlike in the study of Roberts and Lloyd. ${ }^{2}$

Mothers of our boys with hypospadias were not exposed more often than mothers of controls to progestins, other drugs or toxins, or to occupational hazards. They had no higher incidence of threatened abortion or viral infection, or variation in the volume of amniotic fluid.

Kallen, ${ }^{27}$ studying 188 cases from Sweden, showed that women whose sons had hypospadias had a diagnosis of weak contractions more often than controls, a higher rate of inaluced deliveries, and also a higher rate of caesarean sections. This was not the case in our study.

Seven mothers of our cases of hypospadias were diabetic; the diabetes was the insulin dependent type and it was present before pregnancy. Only one of these diabetic women was the mother of an infant with multiple malformations, the child with adrenal hypoplasia. Since the study of Pedersen, ${ }^{28}$ it is worth noting that children of diabetic women are more often malformed than children of non-diabetic mothers, but hypospadias is not considered specific to children of diabetic women.

The question of twinning and hypospadias appears to be more complicated than previously thought. ${ }^{10}$ Previous reports ${ }^{129}$ indicate a higher prevalence of hypospadias in monozygotic twins than in dizygotic twins or singletons. We have observed only seven pairs of twins, five of like sex (males) and two dizygotic twins (male/female); the co-twin was always unaffected. Therefore our material is not sufficient to specify that the presence of two male infants in the same pregnancy increases the risk, and the presence of one male and one female decreases the risk for hypospadias, as was suggested by Kallen et al. ${ }^{10}$

The risk of recurrence for brothers $(17 \cdot 0 \%$, with an empirical risk of about 1 in 6) is higher than that found by Sorensen ${ }^{1}(9 \cdot 6 \%)$, Chen and Woolley ${ }^{15}$ $(9 \cdot 7 \%)$, and Calzolari et $a l^{23}(9 \cdot 1 \%)$, but again our sample is small. Heritability in first degree relatives is $56.9 \%$, which is similar to the heritability calculated by Czeizel et $a l^{7}(65 \%)$, Monteleone et $\mathrm{l}^{8}(68 \%)$, Chen and Woolley ${ }^{15}(74 \%)$, and Calzolari et $a l^{23}(69 \%)$.

Our data are not in favour of the hypothesis that risk factors could facilitate or determine the appearance of hypospadias through an endocrine mechanism.

1 Sorensen HR. Hypospadias with special reference to aetiology. Copenhagen: Munksgaard, 1953.

2 Roberts CJ, Lloyd S. Observations on the epidemiology of simple hypospadias. Br Med f 1973;i:768.

3 Sweet RA, Schrott HG, Kurland R, Culp OS. Study of the incidence of hypospadias in Rochester, Minnesota, 1940-1970, and a case-control comparison of possible etiologic factors Mayo Clin Proc 1974;49:52-8.

4 Avellan L. The incidence of hypospadias in Sweden. Scand $f$ Plast Reconstr Surg 1975;9:129-39.

5 Avellan L. On aetiological factors in hypospadias. Scand 7 Plast Reconstr Surg 1977;11:115-23.

6 Svensson J. Male hypospadias. 625 cases. Associated malformations and possible etiological factors. Acta Paediatr Scand 1979;68:587-92.

7 Czeizel A, Toth J, Erodi E. Aetiological studies of hypospadias in Hungary. Hum Hered 1979;29:166-71.

8 Monteleone R, Castilla EE, Paz JE. Hypospadias: an epidemiological study in Latin America. Am 7 Med Genet 1981;10:5-19.

9 Leung TJ, Baird PA, McGillivray B. Hypospadias in British Columbia. Am $\mathcal{F}$ Med Genet 1985;21:39-48.

10 Kallen B, Bertollini R, Castilla E, et al. A joint international study on the epidemiology of hypospadias. Acta Paediatr Scand [Suppl] 1986;324:1-52.

11 Kemp T. Erbbiologie und erbpathologie des Geschlechtasapparetes. In: Handbuch der Erbbiologie des Menschen. Vol 4. Berlin: Springer Verlag, 1940:939-41.

12 Gates RR. Human genetics. Vol 2. New York: Macmillan, 1948:852-3.

13 Lowry RB, Kliman MR. Hypospadias in successive generations: possible dominant gene inheritance. Clin Genet 1976;9:285-8.

14 Bauer SB, Retik AB, Colodny AH. Genetic aspects of hypospadias. Urol Clin North Am 1981;8:559-64.

15 Chen YC, Woolley PV Jr. Genetic studies on hypospadias in males. F Med Genet 1971;8:153-9.

16 Aarskog D. Maternal progestins as a possible cause of hypospadias. N Engl f Med 1979;300:75-8.

17 Heinonen OP, Sloane D, Shapiro S. Birth defects and drugs in pregnancy. Littleton, Massachusetts: Publishing Sciences Group, 1977.

18 Janerich DT, Piper J, Glebatis DM. Oral contraceptives and birth defects. Am $\mathcal{F}$ Epidemiol 1980;112:73-9.

19 Mau G. Progestins during pregnancy and hypospadias. Teratology $1981 ; 24: 285-7$.

20 World Health Organization. The effects of female sex hormones on fetal development and infant health. WHO Tech Rep Ser No 657. Geneva: WHO, 1981.

21 Polednak AP, Janerich DT. Maternal characteristics and hypospadias: a case-control study. Teratology 1983;28:67-73.

22 Kallen B, Winberg J. An aetiological study of hypospadias in Sweden. Acta Paediatr Scand [Suppl] 1982;239:1-21. 
23 Calzolari E, Contiero MR, Roncarati E, Mattiuz P, Volpato S. Aetiological factors in hypospadias. $\mathcal{F}$ Med Genet 1986;23: 333-7.

24 Roth MP, Dott B, Alembik Y, Stoll C. Malformations congenitales dans une série de 66.068 naissances consécutives. Arch Fr Pediatr 1987;44:173-6.

25 SAS user's guide. Statistics. Cary, NC: SAS Institute, 1988.
26 Falconer DS. The inheritance of liability to certain diseases, estimated from the incidence among relatives. Ann Hum Genet 1965;29:51-76.

27 Kallen B. Case-control study of hypospadias, based on registry information. Teratology 1988;38:45-50.

28 Pedersen J. The pregnant diabetic and her newborn. Baltimore: Williams \& Wilkins, 1967. 